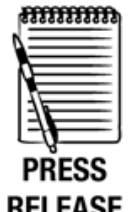

- Additional materials are published online only. To view these files please visit the journal online (http:// injuryprevention.bmj.com/).

${ }^{1}$ Centre for Accident Research and Road Safety-Queensland, Queensland University of Technology, Queensland, Australia

${ }^{2}$ School of Psychology and Counselling, Queensland University of Technology, Queensland, Australia

\section{Correspondence to} Bridie Scott-Parker, Centre for Accident Research and Road Safety-Queensland, Queensland University of Technology (QUT), 130 Victoria Park Road, Kelvin Grove, Queensland 4059, Australia; b.scott-parker@qut.edu.au

Accepted 16 March 2011 Published Online First 16 May 2011

\title{
The psychological distress of the young driver: a brief report
}

\author{
Bridie Scott-Parker, ${ }^{1}$ Barry Watson, ${ }^{1}$ Mark J King, ${ }^{1}$ Melissa K Hyde ${ }^{2}$
}

\begin{abstract}
The objective of the research was to explore the role of psychological distress in the self-reported risky driving of young novice drivers. A cross-sectional online survey incorporating Kessler's Psychological Distress Scale and the Behaviour of Young Novice Drivers Scale was completed by 761 tertiary students aged $17-25$ years with an intermediate (Provisional) driving licence in Queensland, Australia, between August and October 2009. Regression analyses revealed that psychological distress uniquely explained $8.5 \%$ of the variance in young novices' risky driving, with adolescents experiencing psychological distress also reporting higher levels of risky driving. Psychological distress uniquely explained a significant $6.7 \%$ and $9.5 \%$ of variance in risky driving for males and females respectively. Medical practitioners treating adolescents who have been injured through risky behaviour need to be aware of the potential contribution of psychological distress, while mental health professionals working with adolescents experiencing psychological distress need to be aware of this additional source of potential harm. The nature of the causal relationships linking psychological distress and risky driving behaviour are not yet fully understood, indicating a need for further research so that strategies such as screening can be investigated.
\end{abstract}

In Queensland, Australia, in 2008, 13\% of licensed drivers were aged 17-24 years; however, they represented $22.3 \%$ of all road fatalities and were involved in $29.9 \%$ of crashes in which someone was fatally injured. ${ }^{1}$ Risky driving behaviour contributes to crashes involving young novice drivers. Accordingly, the nature and breadth of external and internal influences on the risky driving behaviour of these young drivers is increasingly considered. This brief report investigated the psychological distress of the young driver.

The cognitive, physiological, behavioural and social maturation of young people is often associated with psychological distress such as depression and anxiety, and this can affect their driving behaviour. ${ }^{2}$ The prevalence of depression in adolescence is approximately $24 \%,{ }^{3}$ with one in 10 adolescents being depressed at any given time. ${ }^{4}$ Depression and psychological distress have been associated with risky behaviours, including unprotected sex, ${ }^{5}$ cigarette smoking and unsafe levels of alcohol consumption. ${ }^{6}$

There is mixed evidence about the direction of the relationship between psychological distress and risky behaviour; some findings suggest that distress emerges after risky behaviour, ${ }^{6}$ while others suggest that risky behaviour occurs in response to distress. ${ }^{7}$ Research in Victoria, Australia, compared the self- reported levels of psychological distress for young drivers grouped as low-risk, moderate-risk or highrisk drivers. Anxiety, but not depression, levels between 'low' and 'high' groups were significantly different. $^{8}$ It was concluded that psychological distress was not related to risky driving. Participants rated the riskiness of five driving behaviours (eg, speeding, not wearing seatbelts) within the last 10 journeys only, potentially masking their typical driving behaviour. New South Wales cohort research ${ }^{9}$ similarly found no relationship between psychological distress and subsequent crash involvement; however, the 2-year delay between the measures may have obscured any relationship. ${ }^{10}$ Furthermore, road crashes are comparatively rare events and may not be a sensitive indicator of the extent to which risky behaviour has occurred.

Given the relationship between psychological distress and risky behaviour in adolescents, ${ }^{4-7}$ and that adolescents with an intermediate driver's licence can drive unsupervised, this study explored the role of psychological distress in the risky behaviour of young novice drivers. It was hypothesised that the level of psychological distress would significantly predict young drivers' self-reported risky behaviour, over and above sociodemographic variables associated with risky behaviour in other research. ${ }^{5-7} 11$

\section{METHOD}

\section{Participants}

Drivers ( $\mathrm{n}=761 ; 523$ female) aged 17-25 years (mean $=19, \mathrm{SD}=1.56$ ) with a provisional (intermediate) driver's licence ${ }^{i}$ (281 P1, 480 P2) completed an online survey between August and October 2009.

\section{Design and procedure}

An anonymous cross-sectional online survey was distributed by email of the hyperlink to the registrar of the 13 major tertiary education institutions in Queensland, Australia. Students aged 17-25 years with a provisional driving licence were eligible to participate. Participants were entered into a prize draw for one of four $\$ A 350$ fuel vouchers. Participants reported sociodemographic information (age, gender, licence type, university ${ }^{\text {ii }}$; marital, study, employment status), and completed Kessler's Psychological Distress Scale (K10), ${ }^{12}$

in Queensland, Australia, there are two phases to the provisional (intermediate) driver's licence stage in the graduated driver licensing programme. The novice must hold a provisional 1 (P1) permit for a minimum of 1 year, followed by a provisional 2 (P2) permit for a minimum of 2 years.

iithough there are 13 major tertiary institutions in Queensland, four institutions declined to participate in the research. The variable 'university' was dichotomised as approximately half the participants came from institution 1. 
a 10-item measure of non-specific psychological distress (ie, for mood or anxiety disorder) ( $\alpha=0.91)$. The K10 items align well with criterion A of the DSM-IV (TR) diagnoses of major depressive episode ${ }^{13}$ - higher scores correspond to greater probability that the respondent meets criteria for DSM-IV (TR) or CIDI diagnosis ${ }^{14}$ (please see online supplementary file 1). Participants then rated their agreement with the 44-item Behaviour of Young Novice Drivers Scale ${ }^{15}(\alpha=0.95)$; higher scores indicated higher levels of risky driving behaviour (please see supplementary file 2).

\section{Statistical analyses}

Bivariate correlations were used to explore the strength of association between the K10, sociodemographics and the Behaviour of Young Novice Drivers Scale score. The sample required for hierarchical multiple regression (HMR) exceeded the minimum size of $n \geq 50+8 m$ ( $m=$ number of independent variables) required for a preferred power of $80 \%$, and to detect a medium effect size of $0.20 .^{16}$ The online survey was created using KeySurvey Enterprise Software. Analyses were conducted using SPSS 16.0.

\section{RESULTS}

The K10 scores ranged from 10 to 49 (mean=19.47, SD=7.02, median $=18$, mode=17). When criteria that adjust the K10 thresholds according to the greater psychological distress normatively experienced by adolescents were used, ${ }^{17} 69.5 \%$ experienced no or mild psychological distress (score $<21$ ), $22.9 \%$ experienced moderate distress (score 21-30) and 7.6\% experienced severe psychological distress (score $>31$ ). There was a weak but significant correlation between the K10 and study status (full-time students less distressed) and gender (females more distressed), and a moderate association between the K10 and risky driving behaviour (more distressed corresponds to more risky driving) (table 1$)$.

Sociodemographic variables were dichotomised before HMR: marital status (single $n=451$, relationship $n=310$ ), university (institution $1 \mathrm{n}=392$, other institutions $n=369$ ), study status (full-time $n=705$, other $n=56$ ), employment status (full-time $n=40$, other $n=721$ ). For the HMR, sociodemographics were entered in step 1, the transformed K10 score in step 2, and interactions between centred variables of age and psychological distress (older adolescents experiencing greater psychological distress $^{3}$ ), between gender and distress (females experiencing distress earlier and at greater levels ${ }^{3}$ ), and between the type of

Table 1 Correlations between K10, sociodemographic and risky driving variables

\begin{tabular}{lcc}
\hline & \multicolumn{2}{l}{ Correlations } \\
\cline { 2 - 3 } Variable & K10 score & Risky driving behaviour \\
\hline Age $\dagger$ & 0.03 & -0.06 \\
Gender $\ddagger$ & $0.12^{* *}$ & -0.02 \\
Marital status $\ddagger$ & -0.02 & 0.05 \\
Employment status $\neq$ & -0.01 & -0.03 \\
University $\ddagger$ & -0.05 & -0.05 \\
Study status $\ddagger$ & $0.09^{*}$ & 0.07 \\
Licence type $\ddagger$ & 0.00 & $0.09^{*}$ \\
Risky driving behaviour $\dagger$ & $0.29^{* * *}$ & 1.00
\end{tabular}

${ }^{*} \mathrm{p}<0.05 ;{ }^{* *} \mathrm{p}<0.01 ;{ }^{* * *} \mathrm{p}<0.001$. The Psychological Distress variable was logarithmically transformed to rectify violations of normality.

†Bivariate correlations between continuous variables used Pearson's product moment correlation (r).

$\ddagger$ Bivariate correlations between continuous and dichotomous variables used point biserial correlations $\left(r_{p b}\right)$.

K10, Kessler's Psychological Distress Scale. intermediate licence (as a measure of driving experience) and distress, in step 3. The overall model was significant, $F$ (11, $749)=8.73, p<0.001$ (table 2). At the final step, significant predictors were age (older), licence (P2) and the K10 score (more psychological distress).

Separate HMR analyses for gender were conducted. The model explained a significant $13.7 \%$ of variance in risky driving behaviour for males and $10.2 \%$ for females. The K10 score uniquely accounted for $6.7 \%$ and $9.5 \%$ of the variance for males and females, respectively.

\section{DISCUSSION}

The hypothesis that the level of psychological distress would significantly predict young drivers' self-reported risky behaviour was supported, with the distress of the young drivers explaining $8.5 \%$ of variance in their risky driving after controlling for sociodemographics. Research continues to show that a range of personal characteristics including psychological states can influence driver behaviour and thus crash involvement, and this study provides support for considering the influence of psychological distress. In addition, the K10 has been used only once previously in a sample of young drivers, ${ }^{9} 10$ and this study provides support for such an application of the instrument.

The $\mathrm{K} 10$ is a reliable, inexpensive screening instrument that can be easily incorporated in community surveys. ${ }^{12}$ Moreover, the apparent relationship between $\mathrm{K} 10$ scores and diagnoses of depression indicates that the instrument can identify young drivers who are at greater risk of distress, and therefore at greater risk on the road. Identifying at-risk individuals is vital. ${ }^{18}$ Interventions could be tailored to target particular groups of at-risk drivers, and also from a mental health perspective this may result in improved well-being for the adolescent young driver. The experiences of the adolescent influence the experiences of the adult, including the experience of psychological distress. ${ }^{3}$ It seems reasonable to extend this notion to the adolescent's experiences of risky driving behaviour which has implications

Table 2 Hierarchical multiple regression results for sociodemographic variables, psychological distress and interactions predicting self-reported risky driving behaviour

\begin{tabular}{|c|c|c|c|c|c|c|c|}
\hline Variables & B & SE & B & $\mathbf{s r}^{2}$ & $\mathbf{R}^{2}$ & Adj $R^{2}$ & $\Delta R^{2}$ \\
\hline \multicolumn{8}{|l|}{ Step 1† } \\
\hline Gender & -2.70 & 1.55 & -0.06 & & & & \\
\hline Age & -1.43 & 0.48 & $-0.11^{* *}$ & 0.011 & & & \\
\hline Marital status & 2.04 & 1.47 & 0.05 & & & & \\
\hline University & -1.43 & 1.43 & -0.04 & & & & \\
\hline Study status & 5.05 & 3.25 & 0.07 & & & & \\
\hline Employment status & -1.13 & 3.78 & -0.01 & & & & \\
\hline Licence type & 4.43 & 1.52 & $0.11^{* *}$ & 0.010 & 0.027 & 0.018 & $0.027^{* *}$ \\
\hline \multicolumn{8}{|l|}{ Step $2 \ddagger$} \\
\hline $\begin{array}{l}\text { Psychological } \\
\text { distress }\end{array}$ & 41.99 & 4.93 & $0.30^{* * *}$ & 0.085 & 0.112 & 0.100 & $0.085^{* * *}$ \\
\hline \multicolumn{8}{|l|}{ Step 3§ } \\
\hline $\begin{array}{l}\text { Age-K10 } \\
\text { interaction }\end{array}$ & -0.02 & 0.07 & -0.01 & & & & \\
\hline $\begin{array}{l}\text { Gender-K10 } \\
\text { interaction }\end{array}$ & 0.09 & 0.23 & 0.01 & & & & \\
\hline $\begin{array}{l}\text { Licence-K10 } \\
\text { interaction }\end{array}$ & 0.21 & 0.21 & 0.04 & & 0.114 & 0.101 & 0.001 \\
\hline \multicolumn{8}{|c|}{$\begin{array}{l}{ }^{*} \mathrm{p}<0.05 ;{ }^{*} \mathrm{p}<0.01 ;{ }^{* *} \mathrm{p}<0.001 \text {. The Psychological Distress variable was logarithmically } \\
\text { transformed to rectify violations of normality. Results presented are those at the final step of } \\
\text { analyses. } \\
+F(7,753)=2.97, \mathrm{p}<0.01 \text {. } \\
\neq F(8,752)=11.90, \mathrm{p}<0.001 . \\
\bigotimes F(11,749)=8.73, \mathrm{p}<0.001 \text {. } \\
\mathrm{K} 10 \text {, Kessler's Psychological Distress Scale. }\end{array}$} \\
\hline
\end{tabular}




\section{What is already known on this subject}

- Some novice drivers engage in risky driving behaviour, and this increases their risk of death or injury from a car crash.

- Some adolescents experience psychological distress.

- There is a complex relationship between psychological distress and risky behaviour.

\section{What this study adds}

- The relationship between novice risky driving behaviour and psychological distress has not previously been clearly identified or quantified.

- The psychological distress of young novice drivers in Queensland, Australia, was related to their risky driving behaviour, placing them at greater risk of injury.

for all road users. However, participants in this study may not be representative of all young novice drivers, the research findings are preliminary and definitive recommendations cannot be made without further research.

Strengths of the study include a popular mode of administration, sufficiently large sample and the use of reliable and valid measures applied to the immediate past experience of the drivers, which is important given the potential transience of psychological distress and potential recall problems. Limitations of the study include the cross-sectional nature of the research, the reliance on self-reported data, an over-representation of female participants and non-random sampling of novices. Notwithstanding these limitations, the range of K10 scores (using the original criteria) did not differ from those of a larger sample of Australian young novice drivers. ${ }^{9} 10$ Given that psychosocial development, driving experience and psychological distress are all presumed to change with age, longitudinal research would assist in understanding how the relationships between these variables and risky driving evolve. This research could also consider how distress relates to normative peer influences ${ }^{11}$ and other adolescent risky behaviours such as unprotected sex and drug use ${ }^{6}$ and intentional asphyxiation. ${ }^{19}$

\section{CONCLUSION}

The psychological distress of a sample of young drivers as measured by the K10 was found to predict their risky driving; a contribution over and above that of sociodemographics. The research has implications for road safety researchers and also for medical and mental health professionals. The apparent relationship between $\mathrm{K} 10$ scores and diagnoses of depression ${ }^{20}$ suggests that the instrument may identify young drivers who are at greater risk of distress, and therefore may be at greater risk on the road. Young people presenting to medical and mental health professionals could be screened for current psychological distress, particularly if they have incurred injury through risky behaviour.
Acknowledgement The study reports findings were presented at the $27^{\text {th }}$ International Congress of Applied Psychology, 11-16 July 2010, Melbourne, Australia. The abstract only is included in the conference proceedings.

Participant consent Participants were deemed to consent to participate if they completed the survey. The survey was accompanied by a participant information sheet, and information about the study purpose, risks and benefits expected from participation were repeated at item 1 in the online survey.

\section{Competing interests None.}

Ethics approval This study was conducted with the approval of the Queensland University of Technology.

Contributors The paper reports research undertaken by BSP as part of her PhD programme of research. She completed the literature review, designed the questionnaire, arranged for its administration, analysed the results and discussed the findings. BW, MJK and MJH comprise BSP's PhD supervisory team, and have been involved in providing advice and guidance on all aspects of the project and the writing of the paper. The order of authorship reflects the degree of their contribution.

Provenance and peer review Not commissioned; externally peer reviewed.

\section{REFERENCES}

1. DTMR. Queensland Road Toll 2008. Brisbane: Queensland Government Department of Transport and Main Roads, 2009

2. Dahl RE. Biological, developmental, and neurobehavioral factors relevant to adolescent driving risks. Am J Prev Med 2008;35:S278-84.

3. Avenevoli S, Knight E, Kessler RC, et al. Epidemiology of depression in children and adolescents. In: Abela JRZ, Hankin BL, eds. Handbook of Depression in Children and Adolescents. New York: Guilford Press, 2008:6-34.

4. Strine TW, Mokdad AH, Balluz LS, et al. Depression and anxiety in the United States: findings from the 2006 behavioral risk factor surveillance system. Psychiatr Serv 2008;59:1383-90.

5. Swanholm E, Vosvick M, Chng CL. Pessimism, trauma, risky sex: covariates of depression in college students. Am J Health Behav 2009;33:309-18.

6. Waller MW, Hallfors DD, Halpern CT. Gender differences in associations between depressive symptoms and patterns of substance use and risky sexual behavior among a nationally representative sample of U.S. adolescents. Arch Womens Ment Health 2006;9:139-50.

7. Suris JC, Michaud PA, Akre C, et al. Health risk behaviors in adolescents with chronic conditions. Pediatrics 2008;122:e1113-18.

8. Vassallo S, Smart D, Sanson A, et al. Risky driving among young Australian drivers II: co-occurrence with other problem behaviours. Accid Anal Prev 2008:40:376-86.

9. Martiniuk ALC, Ivers RO, Glozier N, et al. Does psychological distress increase the risk for motor vehicle crashes in young people? Findings from the DRIVE Study. $\checkmark$ Adolesc Health 2010;47:1-8.

10. Ivers RQ, Blows SJ, Stevenson MR, et al. A cohort study of 20822 young drivers: the DRIVE study methods and population. Inj Prev 2006;12:385-9.

11. Scott-Parker B, Watson B, King MJ. Understanding the influence of parents and peers upon the risky behaviour of young drivers. Transp Res Part F Traffic Psychol Behav 2009;12:470-82.

12. Kessler RC, Andrews G, Colpe LJ, et al. Short screening scales to monitor population prevalences and trends in non-specific psychological distress. Psychol Med 2002;32:959-76.

13. Cairney J, Veldhuizen S, Wade TJ, et al. Evaluation of 2 measures of psychological distress as screeners for depression in the general population. Can J Psychiatry 2007:52:111-20.

14. Andrews G, Slade T. Interpreting scores on the Kessler Psychological Distress Scale (K10). Aust N Z J Public Health 2001;25:494-7.

15. Scott-Parker B, Watson B, King MJ. The risky behaviour of young drivers: developing a measurement tool. In: Proceedings of the 20th Canadian Multidisciplinary Road Safety Conference, Niagara Falls, Ontario, June 6-9, 2010.

16. Tabachnick BG, Fidell LS. Using Multivariate Statistics. 3rd edn. New York: Harpe Collins College Publishers, 2006.

17. Huang JP, Xia W, Sun CH, et al. Psychological distress and its correlates in Chinese adolescents. Aust N Z J Psychiatry 2009;43:674-81.

18. Paxton RJ, Valois RF, Watkins KW, et al. Associations between depressed mood and clusters of health risk behaviors. Am J Health Behav 2007;31:272-83. http://www.ajhb.org.

19. Bernadet S. Psychological approach of antisocial behaviours and associated risk-taking behaviours. Inj Prev 2010;16:A264.

20. Furukawa TA, Kessler RC, Slade T, et al. The performance of the K6 and K10 screening scales for psychological distress in the Australian National Survey of Mental Health and Well-Being. Psych Med 2003;33:357-62. 


\section{The psychological distress of the young driver: a brief report}

Bridie Scott-Parker, Barry Watson, Mark J King, et al.

Inj Prev 2011 17: 275-277 originally published online May 16, 2011

doi: 10.1136/ip.2010.031328

Updated information and services can be found at:

http://injuryprevention.bmj.com/content/17/4/275.full.html

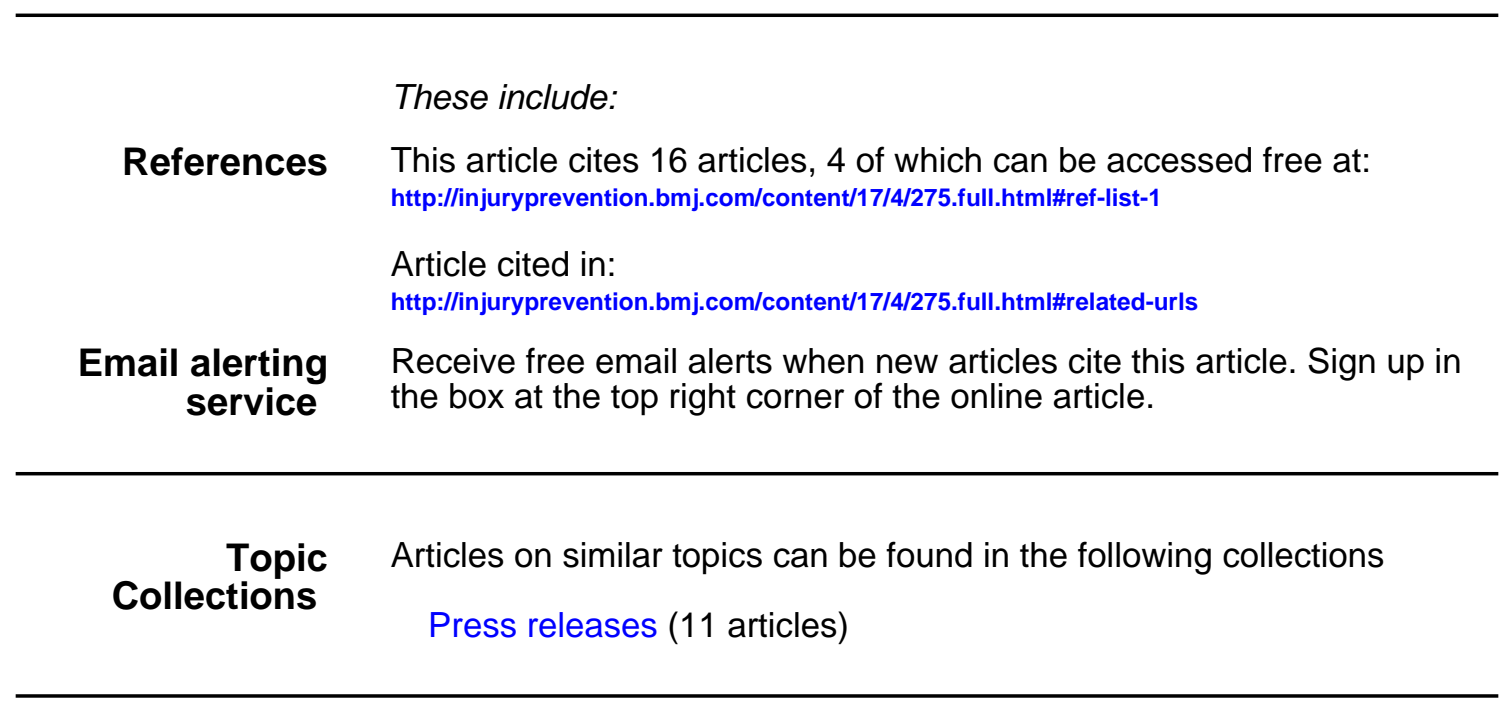

Notes

To request permissions go to:

http://group.bmj.com/group/rights-licensing/permissions

To order reprints go to:

http://journals.bmj.com/cgi/reprintform

To subscribe to BMJ go to:

http://group.bmj.com/subscribe/ 